\title{
CHARLA CON DOMINGO PLÁCIDO SUÁREZ
}

Siempre caben, gracias a la Historia, múltiples posibilidades de imaginar un futuro diferente. Ello justifica que se proclame en ella la investigación sin fin.

Domingo Plácido Suárez ${ }^{1}$

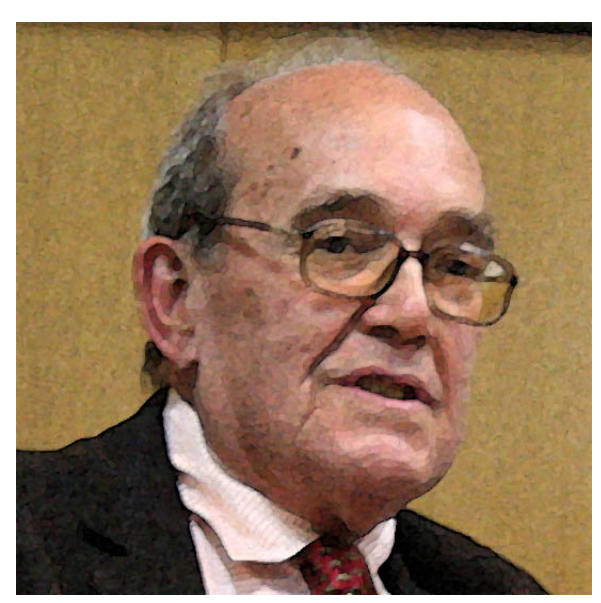

Domingo Plácido Suárez es Doctor en Filosofía y Letras (Filología Clásica). Defendió su Tesis Doctoral, La polis en el pensamiento de Protágoras, dirigida por Santiago Montero Díaz, en 1972. En la actualidad es Catedrático Emérito de Historia Antigua en la Universidad Complutense de Madrid, estando vinculado también al Instituto de Historia del Centro de Ciencias Humanas y Sociales del CSIC, donde colabora con el grupo Estructura Socialy Territorio. Arqueología del Paisaje, dirigido por Javier Sánchez Palencia. Es presidente del Groupe Internationale de Recherche sur l'Esclavage dans L'Antiquité (GIREA) desde 2004 y fue uno de los impulsores de la asociación Antigüedades, Religiones y Sociedades (ARYS) que fomenta un diálogo científico entre investigadores prestigiosos y consolidados, abierto a la participación de jóvenes investigadores, siendo una excepcional plataforma de iniciación para estudiantes y doctorandos en

1 PLÁCIDO SUÁREZ, Domingo, «La historiografía en la Historia Antigua. Las caras del postmodernismo», Revista de Historiografía, 3, 2005, p. 94. 
la investigación en Historia Antigua.

El profesor Plácido Suárez colabora también en los Comités Científicos y de Redacción de varias revistas de reconocido prestigio nacional e internacional como son Anales de Historia Antigua y Medieval, Argos, ARYS, Cuaderno de Estudios Gallegos, Dialogues d'Historie Ancienne, Emerita, Gerión, Hispana Epigráfica, Il Mediterraneo antico, Minius, Studia Historica: Historia Antigua o Tempus.

Ha realizado un enorme trabajo en la implantación y difusión en España de la Historia Antigua desde la Historia Social. Ya a mediados de los 60 se atrevió a traducir Ciencia y Política en el Mundo Antiguo, de Benjamin Farrington, que causaría una auténtica conmoción, y sería la primera obra publicada por la Editorial Ciencia Nueva, fundada por jóvenes estudiantes y que sería todo un símbolo del cambio generacional que estaba teniendo lugar, publicando libros de signo cultural y político opuesto la dictadura ${ }^{2}$.

Desde entonces ha realizado una enorme labor como docente, investigador y divulgador, siendo de destacar la dirección de importantes proyectos de investigación y de tesis doctorales sobre diversos temas de Historia de Grecia, Historia de Roma, y de la Península Ibérica en la Antigüedad. Exponer en detalle el impresionante curriculum del profesor Domingo Plácido Suárez supera enormemente las pretensiones de esta breve semblanza ${ }^{3}$, que no queremos finalizar sin hacer mención a la gran amabilidad con la que nos ha recibido y que quienes han tenido la suerte de tratar con él conocen bien.

2 Sobre la Editorial Ciencia Nueva véase: ROJAS CLAROS, Francisco, «Una editorial para los nuevos tiempos: Ciencia Nueva (1965-1970)», en Historia del Presente, 5, 2005, pp. 103-120.

3 Buenas semblanzas de la trayectoria del profesor Plácido pueden encontrarse en LÓPEZ BARJA DE QUIROGA, Pedro, «Introducción», en PLÁCIDO, Domingo, Poder y discurso en la Antigüedad Clásica, Abada, Madrid, 2008, pp. 5-13; IRIARTE, Ana, «Del mundo antiguo, contestatarios y tardofranquismo: entrevista al Profesor Domingo Plácido Suárez», en FORNIS VAQUERO, César; GALLEGO, Julián; LÓPEZ BARJA DE QUIROGA, Pedro Manuel (coords.), Dialéctica histórica y compromiso social. Homenaje a Domingo Plácido, Pórtico, Zaragoza, 2010, pp. 11-29; VALDÉS GUÍA, Miriam, «Homenaje al profesor Domingo Plácido Suárez», en Studia Historica: Historia Antigua, 28, 2010, pp. 181-189. 
Iván Pérez Miranda, El Futuro del Pasado (FdP): Antes de nada, nos gustaria darle las gracias por su amable participación en El Futuro del Pasado. Comencemos. ¿Desde su punto de vista, qué cree que ha mejorado y qué ha empeorado en la investigación y enseñanza de la Historia Antigua en los últimos años?

Domingo Plácido Suárez (DP): En general, positivo; sólo me quejaría del abandono de algunos problemas y la recuperación de ciertas formas de positivismo, más o menos encubiertas, por ejemplo, cuando algunos se escudan en la falta de datos para eludir interpretaciones arriesgadas.

FdP: Ha dicho usted, en alguna ocasión ${ }^{4}$ que inició su formación en Filología Clásica gracias a la influencia que tuvo en usted Juan Marqués, profesor de Latín durante el bachillerato. ¿Qué recuerdos conserva de este profesory sus enseñanzas?

DP: No sólo hizo atractivo el latín, sino que me reveló la importancia del mismo para el conocimiento y la comprensión de la cultura antigua y la moderna. Al mismo tiempo, me inculcó la afición por todos los aspectos de los debates intelectuales, incluidos los religiosos, junto al amor a la música, muy particularmente a la de Wagner.

FdP: Las humanidades han ido sufriendo un retroceso progresivo en los currículos educativos en las enseñanzas obligatorias. ¿A qué intereses cree que responde este retroceso?

DP: Desde luego, a los mismos que imponen en la docencia el criterio de la rentabilidad productiva. Se impone la tendencia a considerar el criterio de utilidad en el momento de valorar socialmente los conocimientos. Afortunadamente, la Historia puede liberarse de ello, pero a costa de quedar en gran parte marginada en las consideraciones por las que se realizan las inversiones. Sólo aparecen como rentables los estudios que fomentan cierto tipo de propaganda, como la nacionalista, española o autonómica.

FdP: En una entrevista realizada para El País ${ }^{5}$, hace ya algunos años, le preguntaba Santiago Pérez. Diaz, ¿qué han hecho los romanos por nosotros?, quizás como bumorística referencia a la genial película del grupo Monty Python, La Vida de Brian,

4 IRIARTE, Ana, «Del mundo antiguo, contestatarios y tardofranquismo: entrevista al Profesor Domingo Plácido Suárez», en FORNIS VAQUERO, César; GALLEGO, Julián; LÓPEZ BARJA DE QUIROGA, Pedro Manuel (coords.), Dialéctica histórica y compromiso social. Homenaje a Domingo Plácido, Pórtico, Zaragoza, 2010, pp. 11-29, esp. p. 17.

5 PÉREZ DÍAZ, Santiago, «La riqueza del pasado: entrevista a Domingo Plácido», El País, 5-02-2005. Disponible electrónicamente en <http://www.elpais.com/articulo/cultura/ nada/puede/explicar/presencia/civilizacion/romana/elpepicul/20050205elpepicul_8/ Tes> 
en la que Reg, líder del Frente Popular de Judea planteaba la misma pregunta, ¿qué han hecho por nosotros?, «aparte del alcantarillado, la sanidad, la enseñanza, el vino, el orden público, la irrigación, las carreteras y los baños públicos...» Podemos retomar esta cuestión y reformularla de esta manera ¿De qué sirve estudiar lo que bicieron los romanos?

DP: Más que lo que hicieron los romanos, importa intentar comprender cómo lo hicieron, en qué condiciones históricas, a través de qué clase de determinantes, en el seno de qué formas de relacionarse entre sí los seres humanos y, sobre todo, cuáles son las parámetros que diferencian aquella sociedad de la presente.

FdP: Entre 1963 y 1969 usted desempeñó su actividad docente como profesor de instituto. ¿Qué recuerdos guarda de aquella experiencia?

DP: Ejercí la docencia en la enseñanza media durante más tiempo, incluso en coincidencia con la universitaria y mientras hacía la tesis, tanto en la enseñanza privada como en los institutos Brianda de Mendoza de Guadalajara y Pardo Bazán de Madrid. Era una época muy buena para los estudios clásicos y reconozco que, sobre todo en latín, me sirvió para mejorar mi capacidad para la lectura de los textos. Tuve compañeros inolvidables y experiencias determinantes en mi vida. Luego he sabido que las experiencias de los compañeros no son tan positivas.

FdP: El sistema educativo ha cambiado mucho desde entonces. ¿Cómo cree que afecta a la enseñanza de la Historia el hecho de que las competencias educativas recaigan en las Comunidades Autónomas? Un artículo publicado en este número trata sobre la enseñanza de la historia Antigua en el nacionalismo actual de Andalucía ¿ Cree que esta competencia autonómica puede influir en una manipulación del pasado por parte de los partidos en el poder?

DP: No sé si puede influir, pero desde el estudio de la Antigüedad sólo tiene sentido como parte de la Historia Universal, no local. Ésta limita su validez a lo inmediato, como parte de lo que llaman «conocimiento del

6 Reg: But apart from the sanitation, the medicine, education, wine, public order, irrigation, roads, the fresh-water system, and public health, what have the Romans ever done for us?

PFJ Member: Brought peace?

Reg: Oh god, peace, SHUT UP!

(Monty Python's Life of Brian, 1979)

7 ALMANSA FERNÁNDEZ, Marco, «La enseñanza de la historia Antigua en el nacionalismo actual de Andalucía», en El Futuro del Pasado, 2, 2011. 
medio», pero no para comprender la diversidad dinámica de la humanidad en las relaciones personas y colectivas de sus protagonistas.

FdP: También en las Universidades parece que las Humanidades se enfrentan a una crisis importante. ¿Cree que con el Proceso de Bolonia la universidad puede sufrir, como temen muchos, un proceso de mercantilización de la universidad pública que afecte negativamente a las ciencias sociales y bumanas?

DP:- No conozco el Proceso en lo concreto, pero me temo que sí, porque parece responder a esa tendencia general, en la que cuenta la cuantificación como criterio de valoración. El uso del concepto de excelencia encubre el de productividad.

FdP: Como intelectual antifranquista fjaba su descontento en la Iglesia y sus imposiciones morales y de comportamiento, ¿Cómo valora que sigan existiendo capillas en la Universidad Complutense de Madrid? ¿Qué opina de los enfrentamientos entre grupos de estudiantes como la Unión de Historiadores Progresistas (UHP) y los feministas de Luna Nueva, y grupos de "Acción Católica», que se han agravado a raír de los incidentes en torno a la Capilla de Somosaguas', y sobre su repercusión mediática en plena campaña electoral para elegir nuevo equipo rectoral?

DP: Uno de los aspectos más graves de la transición sin ruptura lo representa el papel que desempeña la Iglesia, con frecuencia renovado con el apoyo de gobernantes y jueces, por lo que pienso que cualquier movimiento de protesta está justificado. Sería desde luego conveniente que, sin perder fuerza, no dé pábulo a la justificación de las actitudes descalificatorias, aunque sé que, en esta cuestión y con los medios con que cuenta, la Iglesia no va a abstenerse de usar el arma de la demonización, que con tanta eficacia ha usado siempre.

FdP: Una de sus principales inquietudes ha sido, como dice su discípula Miriam Valdés, «la relación entre el pasado y el presente, la consideración de la Historia Antigua como historia actual y la importancia del pensamiento histórico y de las realidades pretéritas para la comprensión y el análisis de

8 El jueves 10 de marzo, unas 50 jóvenes irrumpieron en la capilla de Somosaguas para leer un manifiesto contra la misoginia de la Iglesia, desnudándose algunas de ellas de cintura para arriba. El 18 de marzo, tras una misa de desagravio, un grupo de «Acción Católica» irrumpió violentamente en la facultad de Geografía e Historia para romper un cartel que pedía la retira de las capillas. Los medios de comunicación se hicieron eco de estas noticias. Desde entonces, la polémica sobre la práctica de la religión en la universidad tomó gran importancia en las campañas de elección del nuevo equipo rectoral. 
la actualidad»?. Su interés por la esclavitudy las distintas formas de dependencia en la Antigüedad le llevó a suceder a Pierre Lèvêque como presidente de GIREA (Groupe international de recherches sur l'esclavage dans l'antiquité). Actualmente, ¿Cuáles considera usted que son las formas de dependencia más preocupantes?

DP: Son muy variadas y potentes a lo largo y ancho del mundo. En septiembre asistí a un congreso en Nottingham del ISOS (Institut of Studies of Slavery), sobre «Trabajo libre», donde escuché intervenciones que, al margen de pocas intervenciones sobre la Antigüedad, iban desde el trabajo infantil hasta la explotación de los chinos por chinos en las ciudades occidentales o la de las mujeres en el Congo. Predominaban los estudios del mundo contemporáneo. Por muy poca inocencia que se conserve ya a cierta edad, no puede dejar de impresionar la crueldad del ser humano cuando se trata de la explotación del trabajo, en un mundo teóricamente civilizado, heredero de la alta cultura de la historia occidental. Da la impresión, además, de que el desarrollo tecnológico sólo ha servido para refinar los modos de dependencia con instrumentos capaces de enmascarar las formas más graves de coerción. Las formas feroces de esclavitud se presentan como si se tratara de trabajo asalariado derivado de la «libertad» del explotador y del explotado.

FdP: Además de incansable investigador y docente, usted ha realizado un gran trabajo como director de importantes tesis doctorales como las de Angel Luis Hoces de la Guardia y Bermejo ${ }^{10}$; Tomás Martín Rodríguez Cerezo $0^{11}$; Inés Sastre Prats ${ }^{12}$; César Antonio Fornis Vaquero ${ }^{13}$; Miriam Valdés Guia ${ }^{14}$; María Cruz Cardete del Olmo ${ }^{15}$. ¿Cómo valora la situación actual de la carrera docente e investigadora?

9 VALDÉS GUÍA, Miriam, «Homenaje al Profesor Domingo Plácido Suárez», SHHA, 28, 2010, pp. 181-189.

10 Dependencia social en Homero. Léxico de las relaciones de dependencia: Odisea. Universidad Complutense de Madrid (1993).

11 Aspectos sociales de la época de Alejandro Magno: sociedad y dependencia personal en la anábasis de Alejandro Magno de Arriano de Nicomedia. Universidad Complutense de Madrid (1998).

12 Formaciones sociales y organización territorial en el Conventus Asturum: la integración en el mundo romano y el proceso histórico durante el Alto Imperio. Universidad Complutense de Madrid (2000).

13 Aproximación a la historia social de Corinto y Argos en la Guerra del Peloponeso (431-415 a.C.). Universidad Complutense de Madrid (2002).

14 La reorganización religiosa en la Atenas del s. VI a.C. Universidad Complutense de Madrid (2003).

15 Paisajes mentales y religiosos de la frontera suroeste arcaica épocas arcaica y clásica. Tesis doctoral codirigida con el prof. Ricardo Olmos Romera. Universidad Complutense de Madrid (2005). 
DP. Veo que hasta ahora ha sido posible iniciar carreras en ese sentido; algunos de los doctores han podido seguir en universidades o centros de investigación. Me parece sin embargo entrever cambios derivados del cierre que halla su pretexto en la «crisis perfecta», como la llama I. Ramonet ${ }^{16}$.

FdP: Finalmente, y tras agradecerle nuevamente su colaboración, ¿qué consejos les daría a un joven que comience el Grado de Historia?, iy a un recién graduado?

(DP): Que piense sobre todo que, si estudia Historia porque siente afición por el conocimiento del pasado humano, tiene que dedicar al estudio grandes esfuerzos, dado que ése es el camino que lleva a sentir auténtico placer en el hecho de penetrar en las dificultades que encierra la comprensión de las complejas relaciones humanas. Una historia anecdótica y no problemática agota su eficacia en breve. Sólo es duradera la satisfacción de saber que siempre es necesario mantener viva la reflexión sobre múltiples problemas entrelazados de forma infinita. Así, aunque sea duro, resultará al mismo tiempo muy satisfactorio.

16 Véase al respecto RAMONET, Ignacio, La catástrofe perfecta, Icaria, Barcelona, 2009. 
